\title{
ISASS Policy 2018-Vertebral Augmentation: Coverage Indications, Limitations, and/or Medical Necessity
}

\author{
OLIVIER CLERK-LAMALICE, MD, FIPP, ${ }^{1}$ DOUGLAS P. BEALL, MD, FIPP ${ }^{2}$ KEVIN ONG, PHD ${ }^{3}$ \\ MORGAN P. LORIO, MD FACS ${ }^{4}$ \\ ${ }^{1}$ Western Canada Pain Institute, Edmonton, Alberta, Canada, ${ }^{2}$ Clinical Radiology of Oklahoma, Edmond, Oklahoma, ${ }^{3}$ Exponent, Inc., Philadelphia, Pennsylvania \\ ${ }^{4}$ Hughston Clinic Orthopaedics-Centennial, Nashville, Tennessee
}

\begin{abstract}
The ISASS Policy Statement on vertebral augmentation has the objectives to provide a background and an update with the latest clinical evidence for the international spine community. A SpineLine Panel Review (2010) appropriately recommended an exploration of "the seeming disconnect between the conclusions of ... two [Level I] PRCT's and previous experience and data" regarding vertebral augmentation. ISASS responded by supporting a comprehensive meta-analysis to help frame a cogent historical analysis of vertebral augmentation. This ISASS Policy 2018 is based on a thorough literature search for relevant studies, including systematic reviews and meta-analyses, that are subjected to thorough quality appraisal for the purpose of informing public opinion and decision making. Given the abundance of high-quality information, ISASS can confidently advocate that there is strong support for vertebral augmentation in the treatment of symptomatic vertebral compression fractures.
\end{abstract}

Testing \& Regulatory Affairs

\section{INTRODUCTION}

Vertebral compression fractures (VCFs) are extremely prevalent and are a hallmark of osteoporosis. The overall age- and sex-adjusted incidence is 117 per 100000 persons per year (145 per 100000 women per year; 73 per 100000 men per year). ${ }^{1}$ These fractures result in pronounced pain in addition to a negative impact on the patient's function and quality of life. Osteoporosis is the most frequent cause for VCFs and is the most important potentially modifiable risk factor for VCFs. Other etiologies, such as neoplasm, trauma, or underlying infection, may also predispose patients to fractures.

Conservative management (bracing and optimal pain management) does not provide adequate longterm pain control while increasing the mortality and morbidity risks of patients secondary to higher risks of cardiac complications and pneumonia. ${ }^{2}$ Moreover, surgical instrumentation has limited utility, as the fixation may not provide sufficient mechanical stability, ${ }^{3}$ resulting in residual pain. Pedicle screws have an additional risk of loosening in osteoporotic bone. $^{4-6}$

VCFs can be treated with minimally invasive interventions, such as percutaneous vertebroplasty and kyphoplasty. Vertebroplasty consists of posi- tioning a trocar (range 8 to 13 gauge) within the vertebral body via a small skin puncture. Cement is then injected with a small cannula with image guidance (fluoroscopic or computed tomography [CT]). Kyphoplasty has similar steps to vertebroplasty; however, a cavity is created within the cancellous bone of the vertebral body prior to cement injection. This cavity can be created in various ways, including with a balloon and a mechanical bone tamp or other mechanical devic$\mathrm{e}(\mathrm{s})$, with the intent of restoring the vertebral body height before filling it with bone cement.

There are 2 types of cement currently available in the United States polymethylmethacrylate (PMMA) and a bioactive calcium phosphate micro-glass cement (Cortoss; Stryker, Malvern, Pennsylvania). PMMA polymerizes and transitions from a liquid to a solid form via an exothermic reaction. The final state of the PMMA does not resorb over time and has an impressive capacity to sustain compressive forces (90 to $110 \mathrm{MPa}$ ). Cortoss is a nonresorbable composite that was developed specifically for vertebral augmentation unlike its older time-proven alternative, PMMA. It consists of $33 \%$ difunctional methacrylates that form a cross-linked 3-dimensional polymer reinforced with $67 \%$ of bioactive glass ceramic. ${ }^{7}$ This 
Table 1. Vertebral augmentation: mortality and morbidity literature.

\begin{tabular}{|c|c|c|c|c|}
\hline Study & Year & $\begin{array}{c}\text { Years } \\
\text { Follow-Up }\end{array}$ & $\mathbf{n}$ & Key Points \\
\hline Edidin et $\mathrm{al}^{14}$ & 2012 & $4+$ & 858978 & $\begin{array}{l}\text { BKP: } 44 \% \text { lower mortality risk than NSM }(\mathrm{AHR}=0.56,95 \% \mathrm{CI} \\
0.55-0.57) \\
\text { VP: } 24 \% \text { lower mortality risk than NSM }(\mathrm{AHR}=0.76,95 \% \mathrm{CI} \\
0.75-0.77)\end{array}$ \\
\hline Chen et $\mathrm{al}^{15}$ & 2013 & $3+$ & 68752 & $\begin{array}{l}\text { BKP: } 32.3 \% \text { lower mortality risk than NSM }(\mathrm{AHR}=0.68,95 \% \mathrm{CI} \\
0.66-0.70) \\
\text { VP: } 15.5 \% \text { lower mortality risk than NSM }(\mathrm{AHR}=0.85,95 \% \mathrm{CI} \\
0.81-0.88)\end{array}$ \\
\hline Lange et $\mathrm{al}^{16}$ & 2014 & $5+$ & 3607 & $\begin{array}{l}\text { VP/BKP: } 43 \% \text { lower mortality risk than NSM }(\mathrm{AHR}=0.57,95 \% \\
\text { CI } 0.48-0.70)\end{array}$ \\
\hline Edidin et al ${ }^{17}$ & 2015 & $4+$ & 1038956 & $\begin{array}{l}\text { NSM: } 55 \% \text { higher mortality risk than BKP }(\mathrm{AHR}=1.55,95 \% \mathrm{CI} \\
1.53-1.56) \text { and } 25 \% \text { higher mortality risk than VP } \\
\text { After propensity matching, the Kaplan-Meier risk of mortality at } 4 \\
\text { years was still found to be greater for the nonoperated cohort } \\
\text { (AHR }=1.62 .95 \% \text { CI } 1.60-1.64)\end{array}$ \\
\hline Ong et $\mathrm{al}^{2}$ & 2017 & $10+$ & 2077944 & $\begin{array}{l}\text { NSM: } 55 \% \text { and } 24 \% \text { higher mortality risk at } 1 \text { year and } 10 \text { years } \\
\text { than BKP (propensity adjusted: } 95 \% \text { CI } 23 \%-24 \%, P<.001 \text { ) } \\
\text { NSM: } 30 \% \text { and } 8 \% \text { higher mortality risk at } 1 \text { year and } 10 \text { years } \\
\text { than VP (propensity adjusted: } 95 \% \text { CI } 8 \%-9 \%, P<.001 \text { ) }\end{array}$ \\
\hline
\end{tabular}

Abbreviations: BKP, balloon kyphoplasty; NSM, nonsurgical management; AHR, adjusted hazard ratio; CI, confidence interval; VP, vertebroplasty.

composite is stronger than PMMA and of similar strength to cortical bone with a much lower exothermic reaction (approximatively $60^{\circ} \mathrm{C}$ with Cortoss versus $70^{\circ} \mathrm{C}-90^{\circ} \mathrm{C}$ with PMMA). ${ }^{7,8}$

The principal goal of vertebral augmentation is to fill the fracture cleft with cement to provide vertebral body mechanical stability. It is this mechanical stability that provides pain relief. The second goal of performing an augmentation procedure is to improve the sagittal alignment and biomechanics of the functional spinal unit (complex of adjacent vertebra). This optimization decreases the probability of refracture within the vertebral body and adjacent-level fractures. Meta-analysis of the literature has demonstrated that vertebral augmentation decreases the prevalence of adjacentlevel fracture; ${ }^{9}$ this is also supported by recent biomechanical experiments. ${ }^{10}$

\section{COVERAGE RATIONALE FOR VERTEBRAL AUGMENTATION}

Typically, vertebral compression fractures are characterized by pain exacerbated by standing erect or with a change of positions (mechanical symptoms). Closed-fist percussion has a sensitivity and specificity of $87.5 \%$ and $90 \%$, respectively. ${ }^{11}$ Advanced imaging is recommended prior to performing vertebral augmentation (magnetic resonance imaging [MRI], CT, or bone scan). When available, MRI should be done.

When left untreated, VCFs significantly increase patients' morbidity and mortality. Cauley et $\mathrm{al}^{12}$ demonstrated that the age-adjusted relative risk of dying was actually higher following a vertebral compression fracture in comparison to a hip fracture (8.64 and 6.68 , respectively). Lau et $\mathrm{al}^{13}$ additionally demonstrated that patients with VCFs have a $40 \%$ lower survival rate at 8 years. Multiple other studies demonstrated the same rationale with a significant increase in mortality and morbidity in patients treated with nonsurgical management when compared to patients who benefited from vertebral augmentation (Table 1).,14-17

Injectable cement remains the main building block for the treatment of painful VCFs. Acrylicbased cements were the first type of cement used to treat fractures in the 1980s. Indeed, the first use of acrylic-based cement (PMMA) in the spine was performed by Galibert et $\mathrm{al}^{18}$ in 1987 as a way to stabilize a vertebral hemangioma. Since then, more than 52 level 1 and level 2 studies were published ${ }^{9,19}$ with the overwhelming majority in favor of the use of vertebral augmentation; some of those studies are shown in Table 2. It is now difficult to argue against the effectiveness of these minimally invasive interventions. Although some studies have argued against the use of vertebral augmentation, questions about the methodological or technical aspects of those studies have been raised. In summary, 3 studies failed to demonstrate superiority of vertebroplasty against a "sham" treatment. 31,36,48 The sham treatments utilized in those 3 studies were in fact active treatments. Moreover, the amount of cement injected was either not reported ${ }^{31}$ or clearly insufficient (ie, an average of $2.8 \mathrm{cc}$ in the Buch- 
Table 2. Vertebral augmentation: level 1 and level 2 studies.

\begin{tabular}{|c|c|c|}
\hline Authors & Year & Results \\
\hline Grafe et $\mathrm{al}^{20}$ & 2005 & $\begin{array}{l}\text { BKP reduces pain, new VCFs, and doctor's visits in chronic osteoporotic VCFs for at least } 1 \mathrm{y} \text {. Both PMMA } \\
\text { and } \mathrm{CaP} \text { equally effective in reducing pain and improving mobility. }\end{array}$ \\
\hline Grohs et $\mathrm{al}^{21}$ & 2005 & $\begin{array}{l}\text { In subacute fractures, BKP is superior in reducing the kyphotic wedge and pain for } 2 \mathrm{y} \text {. Disability } \\
\text { improvement was superior up to } 1 \mathrm{y} \text {. }\end{array}$ \\
\hline Alvarez et $\mathrm{al}^{22}$ & 2006 & $\begin{array}{l}\text { VP is more effective than NSM in pain relief and function in the early postoperative period. No difference } \\
\text { was observed after } 6 \text { mo. }\end{array}$ \\
\hline Diamond et $\mathrm{al}^{23}$ & 2006 & $\begin{array}{l}\text { VP is more effective than NSM in pain relief and function in the early postoperative period. No difference } \\
\text { was observed after } 6 \text { mo. }\end{array}$ \\
\hline De Negri et $\mathrm{al}^{24}$ & 2007 & $\begin{array}{l}\text { VP and BKP offer therapeutic benefit significantly reducing pain and improving mobility in patients with } \\
\text { vertebral fracture. Cement extravasation occurred only during PV. }\end{array}$ \\
\hline Voormolen et $\mathrm{al}^{25}$ & 2007 & VP is more effective than NSM in pain relief and function in the immediate postoperative period ( $2 \mathrm{wk})$. \\
\hline Wardlaw et $\mathrm{al}^{26}$ & 2009 & $\begin{array}{l}\text { BKP is superior to NSM in acute VCFs in terms of pain and QOL/disability. Differences between groups } \\
\text { diminished by } 1 \mathrm{y} \text {. }\end{array}$ \\
\hline Dong et $\mathrm{al}^{27}$ & 2009 & $\begin{array}{l}\text { Both procedures (BKP and VP) have significant pain relief and improve lung function; BKP improves vital } \\
\text { capacity more than VP. }\end{array}$ \\
\hline Lovi et $\mathrm{al}^{28}$ & 2009 & Similar pain relief and function score (BKP and VP) BKP less cement leakage. \\
\hline Schofer et $\mathrm{al}^{29}$ & 2009 & Similar pain relief (BKP versus VP) and QOL. BKP less cement leakage and improve fracture reduction. \\
\hline Rousing et $\mathrm{al}^{30}$ & 2009 & Immediate pain reduction but no difference between VP and NSM in 3 mo and 12 mo. \\
\hline Kallmes et $\mathrm{al}^{31}$ & 2009 & No difference between VP and sham up to $1 \mathrm{mo}$. \\
\hline Rollinghof et $\mathrm{al}^{32}$ & 2009 & Mean vertebral body height restoration was significantly $(P<.05)$ higher in BKP. \\
\hline Santiago et $\mathrm{al}^{33}$ & 2010 & No difference between operations (BKP versus VP). \\
\hline Kasperk et $\mathrm{al}^{34}$ & 2010 & $\begin{array}{l}\text { Kyphoplasty reduces pain and improves mobility as long as } 3 \mathrm{y} \text { after the procedure. The long-term risk of } \\
\text { new vertebral fractures after kyphoplasty of chronically painful vertebral fractures is reduced versus } \\
\text { controls. }\end{array}$ \\
\hline Liu et $\mathrm{al}^{35}$ & 2010 & Similar clinical results between BKP and VP. Better height restoration with BKP. \\
\hline Buchbinder et $\mathrm{al}^{36}$ & 2010 & No difference between VP and sham up to 6 mo. \\
\hline Klazen et $\mathrm{al}^{37}$ & 2010 & VP is more effective than NSM in acute fractures for at least $1 \mathrm{y}$. \\
\hline Bae et $\mathrm{al}^{38}$ & 2010 & Both BKP and VP were equally effective in improving pain and disability/QOL. \\
\hline Movrin et $\mathrm{al}^{29}$ & 2010 & $\begin{array}{l}\text { Both BKP and VP were equally effective in improving pain and have low incidence of new VCFs. BKP had } \\
\text { greater kyphosis correction. }\end{array}$ \\
\hline Kumar et $\mathrm{al}^{40}$ & 2010 & $\begin{array}{l}\text { Both BKP and VP were equally effective in improving pain, disability and QOL; BKP yielded greater results } \\
\text { maintained until last follow-up. }\end{array}$ \\
\hline Farrokhi et $\mathrm{al}^{41}$ & 2011 & $\begin{array}{l}\text { PV group had statistically significant improvements in visual analog scale and QOL scores maintained over } 24 \\
\text { mo, improved vertebral body height maintained over } 36 \mathrm{mo} \text {, and fewer adjacent-level fractures compared } \\
\text { with the optimal medical therapy group. }\end{array}$ \\
\hline Berenson et $\mathrm{al}^{42}$ & 2011 & $\begin{array}{l}\text { Painful VCFs in patients with cancer. BKP is an effective and safe treatment that rapidly reduces pain and } \\
\text { improves function. }\end{array}$ \\
\hline Blasco et $\mathrm{al}^{43}$ & 2012 & $\begin{array}{l}\text { VP achieved faster pain relief with significant improvement in the pain score at the 2-mo follow-up but was } \\
\text { associated with a higher incidence in vertebral fractures. }\end{array}$ \\
\hline Roder et $\mathrm{al}^{44}$ & 2013 & Cement volume is the most important predictor for pain relief in BKP. \\
\hline VanMeirhaeghe et $\mathrm{al}^{45}$ & 2013 & $\begin{array}{l}\text { Compared with NSM, BKP improves patient quality of life and pain averaged during } 24 \text { mo and results in } \\
\text { better improvement of index vertebral body kyphotic angulation. }\end{array}$ \\
\hline Clark et al ${ }^{46}$ & 2016 & $\begin{array}{l}\text { Reduction in proportion of patients with low pain score at all time points in favor of vertebroplasty. } \\
\text { Reduction in mean pain scores at all time points in favor of vertebroplasty. Reduction in RMDQ score at } \\
1,3 \text {, and } 6 \text { mo in favor of vertebroplasty. Maintained vertebral body height versus further collapse in the } \\
\text { placebo group. Reduction in duration of hospitalization providing probable cost savings in favor of } \\
\text { vertebroplasty. }\end{array}$ \\
\hline Beall et $\mathrm{al}^{47}$ & 2018 & $\begin{array}{l}\text { At the } 3 \text {-mo primary end point, BKP NRS improved from } 8.7 \text { to } 2.7(P<.001) \text {, and ODI improved from } \\
63.4 \text { to } 27.1(P<.001) \text {. These outcomes were statistically significant at every follow-up time point. BKP is } \\
\text { a safe, effective, and durable procedure for treating patients with painful VCFs due to osteoporosis or } \\
\text { cancer. }\end{array}$ \\
\hline Firanescu et $\mathrm{al}^{48}$ & 2018 & No difference between VP and SHAM up to 12 mo among patients with acute osteoporotic VCFs. \\
\hline
\end{tabular}

Abbreviations: BKP, balloon kyphoplasty; VCF, vertebral compression fracture; PMMA, polymethylmethacrylate; CaP, calcium phosphate; VP, vertebroplasty; NSM, nonsurgical management; QOL, quality of life; RMDQ, Roland-Morris Disability Questionnaire; ODI, Oswestry Disability Index.

binder et al ${ }^{36}$ study and ranging from 1 to $11 \mathrm{cc}$ in the Firanescu et $\mathrm{al}^{48}$ study). Others have also detailed flaws of the construct of those studies related to patient selection, low visual analog scale (VAS) score at baseline, and underpowered studies $^{49,50}$ as well as inadequate inclusion criteria and a subsequent high crossover rate. ${ }^{51}$

The cost-effectiveness of vertebral augmentation has been demonstrated in prior studies. ${ }^{15,52}$ Conservative management of females with vertebral compression fractures results in incremental costs for the health care system even at 5 years after the VCF ${ }^{53}$ From the perspective of elderly patients in the United States, balloon kyphoplasty and vertebroplasty have been found to be cost effective in terms of cost per life year gained compared with nonsurgical management, even for the oldest patients. ${ }^{54}$ Interestingly, Lange et $\mathrm{al}^{16}$ demonstrated that using German claim data, although the initial cost of the intervention is higher, balloon 
kyphoplasty is more cost effective than vertebroplasty by providing better pain control and decreasing costs related to oral narcotics in addition to providing survival benefit. Edidin et $\mathrm{al}^{54}$ studied the US Medicare data set and also reported that balloon kyphoplasty was cost effective and perhaps even cost saving when compared with vertebroplasty.

Overall, kyphoplasty has demonstrated better performance than vertebroplasty for patient treatment. When available, kyphoplasty should be preferentially performed. Indeed, adjusted life expectancy is $85 \%$ greater for patients who have had vertebral augmentation in comparison to patients treated conservatively, corresponding to a median life expectancy improvement of from 2.2 to 7.3 years. ${ }^{14}$ Kyphoplasty patients have $115 \%(P$ $<.001 ; 95 \%$ confidence interval [CI]: $111 \%-119 \%$ ) greater life expectancy than patients treated conservatively. On the other hand, vertebroplasty has a 44\% $(P<.001 ; 95 \%$ CI: 42\%-47\% $)$ increase compared with conservatively treated patients. Direct comparison between vertebroplasty and kyphoplasty demonstrates a 34\% $(P<.001 ; 95 \%$ CI: $31 \%-36 \%$ ) increase in adjusted life expectancy in favor of the kyphoplasty cohort. Based on these results and on the RAND/UCLA Appropriateness Method, experts agree that balloon kyphoplasty should be preferentially used in almost all circumstances. ${ }^{55}$

\section{PUBLISHED LITERATURE}

\section{Prior to 2009}

Prior to 2009, the literature was favorable toward vertebral augmentation procedures. In fact, a systematic review of the published data prior to 2006 concluded that this procedure was safe and provided pain relief in $87 \%$ of patients with vertebroplasty and $92 \%$ of patients with kyphoplasty. ${ }^{56}$ Also, cement leakages were lower in patients treated with kyphoplasty in comparison to vertebroplasty $(9 \%$ versus $41 \%)$. However, the authors of this review suggested that randomized clinical trials were lacking at the time. One year later (in 2007), the VERTOS I study followed with the randomization of 34 patients separated into 2 treatment arms; 1 group was treated with vertebroplasty and the other with conservative therapy. This prospective short-term clinical outcome assessment at 2 weeks demonstrated all QUALEFFO quality- of-life questionnaire and Roland-Morris Disability Questionnaire (RMDQ) scores to be better compared to scores during conservative management. ${ }^{25}$

\section{Publication of the 2009 New England Journal of Medicine Sham-Controlled Studies}

In 2009, Buchbinder et $\mathrm{al}^{36}$ published a multicenter double-blind prospective randomized controlled trial (RCT) comparing patients treated with vertebroplasty with a sham procedure. Thirty-eight patients were treated with vertebroplasty and 40 with a sham procedure. This sham procedure consisted of inserting a 13-gauge needle within the periosteum (arguably a mechanical rhizotomy). Metrics of pain, quality of life, and disability failed to demonstrate a difference between groups at 1 week, 3 months, or 6 months. ${ }^{36}$ Another multicenter RCT, the Investigational Vertebroplasty Safety and Efficacy Trial, was published concurrently by Kallmes et al, ${ }^{31}$ evaluating 131 patients with 1 to 3 VCFs. Those patients were divided in the treatment arm (68 vertebroplasties) or a sham group (63 injections of anesthetic on the periosteum, arguably performing medial branch blocks). The primary outcomes were scores on the modified RMDQ and patients' pain scores. The sham groups of those studies consisted of performing mechanical rhizotomies by inserting a 13-gauge needle through the medial branch of the dorsal rami and through the periosteum ${ }^{36}$ in addition to blocking this same nerve with anesthetic at the junction of the superior articular process and the transverse process. $^{31}$

The amount of cement injected is the most important modifiable parameter to ensure treatment success. ${ }^{44}$ In these 2 New England Journal of Medicine $(N E J M)$ studies, the amount of cement injected was either not reported ${ }^{31}$ or clearly insufficient (ie, an average of $2.8 \mathrm{~mL}$ in the Buchbinder et $\mathrm{al}^{36}$ study). Other studies have detailed more study construct flaws related to patient selection (lack of physical examination performed), low pain intensity score considered as an inclusion criteria (VAS of 3 in the Kallmes et $\mathrm{al}^{32}$ study), and underpowered studies. ${ }^{49,50}$ Finally, a recent meta-analysis by Anderson et $\mathrm{al}^{54}$ downgraded both the 2009 NEJM studies by Kallmes and Buchbinder from a level I to a level II due to inclusion criteria and subsequent high crossover. 


\section{Impact of the Equivocal 2009 NEJM Sham- Controlled Studies}

Unfortunately, after the publication of the 2009 NEJM studies, a decrease in the volume of vertebral augmentation reimbursement by insurance companies was noticed. Also, the "mainstream" literature published on the UpToDate website, at Wikipedia. com, and in the Hayes reports became unfavorable toward vertebral augmentation.

Furthermore, in 2010, the AAOS Clinical Practice Guidelines recommended against vertebroplasty for patients who presented with osteoporotic compression fracture. Also, the guidelines classified the evidence of support of kyphoplasty as limited. ${ }^{57}$

These new guidelines, in addition to the disseminated information, resulted in a decrease of the augmentation volume between 2005 and 2014. In fact, vertebral augmentation (kyphoplasty and vertebroplasty) in the US Medicare population utilization was $20 \%$ in 2005 , peaked at $24 \%$ in $2007-2008$, and declined to $14 \%$ in 2014 . In turn, the 5-year period following 2009 was associated with significant elevated mortality risk in VCF patients, ${ }^{2}$ and notyet-published data estimated that up to 6814 extra lives may have been lost during this period directly due to the change in treatment patterns.

\section{Studies Published After 2009: Vertebroplasty}

In 2010, VERTOS II, an RCT, evaluated 101 patients treated with vertebroplasty versus 101 patients treated with conservative treatment. One month after the intervention, the differences in VAS score between baseline were measured (delta of -5.2 after vertebroplasty and -2.7 after conservative treatment), and the same measurements were performed 1 year after the intervention (delta of -5.7 after vertebroplasty and -3.7 after conservative management). These results highlighted, for the first time after the 2009 NEJM studies, the long-lasting pain relief provided by vertebroplasty in comparison to conservative management.

The VAPOUR trial, published in 2016, is a multicenter, randomized, double-blind, placebocontrolled trial that included 120 patients; 61 were assigned to the vertebroplasty arm and 59 to the placebo arm. Only patients with 1 or 2 osteoporotic vertebral compression fractures of less than 6 weeks' duration were included in the study. Also, patients had to have numerical rating scale (NRS) back pain greater than or equal to 7 out of 10 . Vertebroplasty was performed with an adequate amount of cement $(7.5 \mathrm{~mL}, \mathrm{SD}=2.8 \mathrm{~mL})$. The placebo arm in this study consisted of injecting lidocaine subcutaneously without any periosteal numbing. Patient followup was performed for 6 months. The primary outcome was the proportion of patients who had an NRS score below 4 out of 10 at 14 days postintervention; $44 \%$ of patients in the vertebroplasty group and $21 \%$ in the control group had an NRS pain score below 4 out of 10 at 14 days. ${ }^{46}$

More recently, the VOPE trial, a trial that evaluated a sham procedure for painful acute osteoporotic vertebral fractures, evaluated 46 patients: 22 in the vertebroplasty arm and 24 in the sham arm. Patients in the sham group received only periosteal lidocaine injection. The results of this study also demonstrate statistically lower VAS scores in the vertebroplasty group at 3 months, and the results are still pending publication. ${ }^{58}$

The VERTOS II, VAPOUR, and VOPE trials demonstrated the highest level of evidence supporting vertebroplasty.

\section{Studies Published After 2009: Kyphoplasty}

For kyphoplasty, there has been 1 RCT (the FREE trial) ${ }^{59}$ and 1 postmarket trial (the EVOLVE trial $)^{47}$ clearly demonstrating the benefit of this treatment. Indeed, the FREE trial evaluated 300 patients (149 treated by balloon kyphoplasty and 151 with optimal pain management). In the balloon kyphoplasty group, the mean SF-36 PCS score improved by 7.2 points at 1 month and by 2.0 points in the nonsurgical group. Interestingly, in this study, a correlation between the kyphotic angle and pain reduction was noted. ${ }^{60}$

The EVOLVE trial, a postmarket trial and the largest vertebral augmentation study to date (354 patients treated with kyphoplasty), was developed to investigate the disability, quality of life, and safety outcomes of a Medicare-eligible population. Patients were evaluated at baseline, 7 days, and 1, 3, 6, and 12 months with 4 coprimary end points: NRS, ODI, SF-36v2 PCS, and EQ-5D. The improvements in these outcomes were statistically significant at every time point. ${ }^{47}$

\section{Systematic Reviews and Meta-Analyses}

A number of systematic reviews and metaanalyses have also been reported in the literature. Papanastassiou et $\mathrm{al}^{9}$ analyzed 27 level 1 and level 2 prospective multiarmed studies with cohorts of at 
least 20 patients and found that vertebral augmentation provided greater pain relief and fewer subsequent fractures than nonsurgical management in osteoporotic VCFs. Balloon kyphoplasty was also found to be marginally favored over vertebroplasty in disability improvement and significantly favored in quality-of-life improvement. Balloon kyphoplasty also had a lower risk of cement extravasation and resulted in greater kyphosis correction over vertebroplasty.

A meta-analysis of RCTs comparing either vertebroplasty or kyphoplasty to conservative or sham treatment for osteoporotic compression fractures was identified and reviewed by Anderson et al. ${ }^{54}$ Based on 6 studies that were included in the quantitative analysis, cement augmentation was found to result in greater pain relief, functional recovery, and health-related quality of life than nonoperative or sham treatment.

Beall et $\mathrm{al}^{47}$ performed a meta-analysis that built on the work of Papanastassiou et al. ${ }^{9}$ This review of 25 more recent level 1 and level 2 studies showed that balloon kyphoplasty had significantly better and that vertebroplasty tended to have better pain reduction in terms of VAS compared with nonsurgical management. Balloon kyphoplasty also tended to have better vertebral body height restoration than vertebroplasty. ${ }^{19}$

\section{The 2013 Kyphoplasty and Vertebroplasty National Institute for Health and Care Excellence Technology Appraisal Guidance}

The 2013 National Institute for Health and Care Excellence (NICE) technology appraisal guidance concluded that there was sufficient evidence to state that vertebral augmentation procedures are more effective in reducing pain and restoring vertebral body height than optimal pain management in people with recent, painful, unhealed osteoporotic VCFs. ${ }^{59}$ These conclusions were made after careful evaluation of the relevant literature at the time, including the 22009 NEJM studies. $^{25,30,31,35-37,41,43,60}$ Both vertebroplasty and kyphoplasty were judged to be cost effective at the time. The panel for this report noted a statistically significant mortality benefit for both vertebroplasty and kyphoplasty in comparison to optimal pain management.

Since then, new studies have been published proving the pain relief benefit of these procedures ${ }^{46,47}$ in addition to new data on the mortality and morbidity ${ }^{2,15-17}$ that further reinforced the body of knowledge supporting the treatment of clinical VCFs.

\section{Publication and Impact of the VERTOS IV Study}

In 2018, the VERTOS IV study evaluated 180 participants randomized to either a vertebroplasty $(\mathrm{n}=91)$ or a sham $(\mathrm{n}=89)$ procedure. The main outcome consisted of the VAS scores at 1 day, 1 week, and 1, 3, 6, and 12 months. Secondary outcome measures were the differences between groups for changes in the quality of life for osteoporosis and RMDQ scores at the 12-month follow-up. ${ }^{48}$ This study failed to demonstrate statistically significant pain relief in the group treated with vertebroplasty in comparison to the sham procedure.

There was concern that the published VERTOS IV study would have a similar impact as the 2009 NEJM studies. However, the current body of literature strongly favors these procedures (more than 52 level 1 and level 2 studies supporting these therapies and 3 metanalyses), and the medical community seems less impacted in comparison to the 2009 NEJM studies.

The methodology of VERTOS IV has some similarities with the 2009 NEJM studies. First, the sham group represents active treatment. Indeed, the periosteum and medial branch of the dorsal rami were blocked with $1 \%$ lidocaine and $0.25 \%$ bupivacaine. Additionally, both the vertebroplasty arm and the sham arm had bilateral mechanical rhizotomy since 2 trocars were positioned with a transpedicular approach. Second, patient selection and follow-up in this study raised some concerns since the physician evaluating the patient prior to the intervention and performing the clinical followup was not an interventional pain specialist but rather an internist. Third, the amount of cement injected reported in this study ranged from 1 to 11 $\mathrm{mL}$. It is unlikely that a patient with only $1 \mathrm{cc}$ of cement would have an optimal result. ${ }^{3}$ Regardless of this very important point, there was no mention of refracture, insufficient cement filling, or adjacentlevel fractures in this study, all commonly seen $(\sim 15 \%)$ in a service with busy vertebral augmentation volume.

\section{CLINICAL INDICATION OF COVERAGE}

Patients who have all of the following criteria may be eligible for vertebral augmentation: 
- Severe functional limitation due to pain or hospitalization due to a VCF

- History of VCFs: minimal or low-velocity fracture

- Physical examination consistent with VCFs: tenderness with palpation or percussion over the spinous process

- Fracture confirmed by advanced imaging (MRI, CT, bone scan)

Contraindication to vertebral augmentation:

- Presence of blood-borne infection, infection at the surgical site, and/or osteomyelitis

As suggested by the RAND/UCLA Clinical Care Pathway for the management of VCFs, ${ }^{61}$ the time since the fracture is now considered less relevant for the treatment of patients.

\section{CODING}

In general, vertebral augmentation refers to surgical procedures that increase or augment the structural integrity of a fractured/compromised vertebral body. Vertebral augmentation encompasses different techniques, the most common of which are vertebroplasty and kyphoplasty.

However, for the purposes of coding, Current Procedural Terminology (CPT) defines "vertebroplasty" as "the process of injecting material (cement) into the vertebral body to reinforce the structure of the body using image guidance." Vertebroplasty is reported with CPT codes 22510, 22511, and 22512.

CPT defines "vertebral augmentation" as "the process of cavity creation followed by the injection of the material (cement) under image guidance." By this definition, kyphoplasty is classified as vertebral augmentation and reported with CPT codes 22513, 22514, and 22515.

When reporting vertebroplasty or vertebral augmentation (kyphoplasty), the code selection is dependent on location and number of segments treated and is inclusive of bone biopsy, when performed, and imaging guidance necessary to perform the procedure:

- 22510 Percutaneous vertebroplasty (bone biopsy included when performed), 1 vertebral body, unilateral or bilateral injection, inclusive of all imaging guidance; cervicothoracic

- 22511 Lumbosacral
- 22512 Each additional cervicothoracic or lumbosacral vertebral body (list separately in addition to primary procedure)

- 22513 Percutaneous vertebral augmentation, including cavity creation (fracture reduction and bone biopsy included when performed) using mechanical device (eg, kyphoplasty), 1 vertebral body, unilateral or bilateral cannulation, inclusive of all imaging guidance; thoracic

- 22514 Lumbar

- 22515 Each additional thoracic or lumbar vertebral body (list separately in addition to code for primary procedure)

\section{DOCUMENTATION REQUIREMENTS}

- A complete history and physical documenting the vertebral compression fracture.

- Imaging findings concordant with the physical examination. Advanced imaging should be performed prior to vertebral augmentation (MRI, CT, bone scan). When available, MRI should be performed. ${ }^{55}$

- A course of conservative treatment is no longer required prior to treat the fracture, as earlier treatment provides better results and decreases mortality and morbidity related to vertebral compression fractures. ${ }^{2}$

- Although the surgical approach to the vertebral body can be similar to vertebroplasty, vertebral augmentation (kyphoplasty) is a different procedural terminology and requires that one document the use of a mechanical device for cavity creation (fracture reduction) prior to injection of material (cement).

\section{COVERAGE/CONCLUSION}

Vertebral augmentation procedures (vertebroplasty and kyphoplasty) are safe and effective procedures that have been highly studied. The level 1 evidence is overwhelmingly in favor of vertebral augmentation when compared to conservative management. Failure to treat patients with painful VCFs has been associated with an increased mortality and morbidity. ISASS endorses the early treatment of painful VCFs with vertebral augmentation procedures (vertebroplasty and preferentially kyphoplasty). ISASS does not endorse any specific vertebroplasty/ kyphoplasty system. There are 
numerous systems available that have received $510(\mathrm{~K})$ for use in VCFs. The system used and vertebral levels augmented are the purview of the surgeon.

\section{REFERENCES}

1. Cooper C, Atkinson EJ, O'Fallon WM, Melton LJ. Incidence of clinically diagnosed vertebral fractures: a population-based study in Rochester, Minnesota, 1985-1989. J Bone Miner Res. 1992;7(2):221-227.

2. Ong KL, Beall DP, Frohbergh M, Lau E, Hirsch JA. Were VCF patients at higher risk of mortality following the 2009 publication of the vertebroplasty "sham" trials? Osteoporos Int. 2017;29(11):2520-2529.

3. Röder C, Boszczyk B, Perler G, Aghayev E, Külling F, Maestretti G. Cement volume is the most important modifiable predictor for pain relief in BKP: results from SWISSspine, a nationwide registry. Eur Spine J. 2013;22(10):2241-2248.

4. Tomé-Bermejo F, Piñera AR, Alvarez-Galovich L. Osteoporosis and the management of spinal degenerative disease (I). Arch Bone Joint Surg. 2017;5(5):272-282.

5. Tomé-Bermejo F, Piñera AR, Alvarez L. Osteoporosis and the management of spinal degenerative disease (II). Arch Bone Joint Surg. 2017;5(6):363-374.

6. Wu Z-X, Gong F-T, Liu L, et al. A comparative study on screw loosening in osteoporotic lumbar spine fusion between expandable and conventional pedicle screws. Arch Orthop Trauma Surg. 2012;132(4):471-476.

7. Bae H, Hatten HP, Linovitz R, et al. A prospective randomized FDA-IDE trial comparing Cortoss with PMMA for vertebroplasty: a comparative effectiveness research study with 24-month follow-up. Spine (Phila Pa 1976). 2012;37(7):544-550.

8. Jacobson RE, Granville M, Hatgis J, Berti A. Low volume vertebral augmentation with Cortoss $^{\circledR}$ cement for treatment of high degree vertebral compression fractures and vertebra plana. Cureus. 2017;9(2):1-10.

9. Papanastassiou ID, Phillips FM, Meirhaeghe J, et al. Comparing effects of kyphoplasty, vertebroplasty, and nonsurgical management in a systematic review of randomized and non-randomized controlled studies. Eur Spine J. 2012;21(9):1826-1843.

10. Luo J, Annesley-Williams DJ, Adams MA, Dolan P. How are adjacent spinal levels affected by vertebral fracture and by vertebroplasty? A biomechanical study on cadaveric spines. Spine J. 2017;17(6):863-874.

11. Langdon J, Way A, Heaton S, Bernard J, Molloy S. Vertebral compression fractures-new clinical signs to aid diagnosis. Ann R Coll Surg Engl. 2010;92(2):163-166.

12. Cauley JA, Thompson DE, Ensrud KC, Scott JC, Black D. Risk of mortality following clinical fractures. Osteoporos Int. 2000;11(7):556-561.

13. Lau E, Ong K, Kurtz S, Schmier J, Edidin A. Mortality following the diagnosis of a vertebral compression fracture in the Medicare population. J Bone Joint Surg Am. 2008;90(7):1479-1486.

14. Edidin AA, Ong KL, Lau E, Kurtz SM. Life expectancy following diagnosis of a vertebral compression fracture. Osteoporos Int. 2012;24(2):451-458.
15. Chen AT, Cohen DB, Skolasky RL. Impact of nonoperative treatment, vertebroplasty, and kyphoplasty on survival and morbidity after vertebral compression fracture in the Medicare population. J Bone Joint Surg Am. 2013;95(19):1729-1736.

16. Lange A, Kasperk C, Alvares L, Sauermann S, Braun S. Survival and cost comparison of kyphoplasty and percutaneous vertebroplasty using German claims data. Spine. 2014;39(4):318-326.

17. Edidin AA, Ong KL, Lau E, Kurtz SM. Morbidity and mortality after vertebral fractures: comparison of vertebral augmentation and nonoperative management in the Medicare population. Spine (Phila Pa 1976). 2015;40(15):1228-1241.

18. Galibert P, Deramond H, Rosat P, Le Gars D. [Preliminary note on the treatment of vertebral angioma by percutaneous acrylic vertebroplasty]. Neurochirurgie. 1987;33(2):166-168.

19. Beall D, Lorio MP, Yun BM, Runa MJ, Ong KL, Warner CB. Review of vertebral augmentation: an updated meta-analysis of the effectiveness. Int. J. Spine Surg. 2018;12(3):295-321.

20. Grafe IA, Da Fonseca K, Hillmeier J, et al. Reduction of pain and fracture incidence after kyphoplasty: 1-year outcomes of a prospective controlled trial of patients with primary osteoporosis. Osteoporos Int. 2005;16(12):2005-2012.

21. Grohs JG, Matzner M, Trieb K, Krepler P. Minimal invasive stabilization of osteoporotic vertebral fractures: a prospective nonrandomized comparison of vertebroplasty and balloon kyphoplasty. J Spinal Disord Tech. 2005;18(3):238-242.

22. Alvarez L, Alcaraz M, Pérez-Higueras A, et al. Percutaneous vertebroplasty: functional improvement in patients with osteoporotic compression fractures. Spine. 2006;31(10):1113-1118.

23. Diamond TH, Bryant C, Browne L, Clark WA. Clinical outcomes after acute osteoporotic vertebral fractures: a 2-year non-randomised trial comparing percutaneous vertebroplasty with conservative therapy. Med J Aust. 2006;184(3):113-117.

24. De Negri P, Tirri T, Paternoster G, Modano P. Treatment of painful osteoporotic or traumatic vertebral compression fractures by percutaneous vertebral augmentation procedures: a nonrandomized comparison between vertebroplasty and kyphoplasty. Clin J Pain. 2007;23(5):425-430.

25. Voormolen MHJ, Mali WPTM, Lohle PNM, et al. Percutaneous vertebroplasty compared with optimal pain medication treatment: short-term clinical outcome of patients with subacute or chronic painful osteoporotic vertebral compression fractures. The VERTOS study. Am J Neuroradiol. 2007;28(3):555-560.

26. Wardlaw D, Cummings SR, Van Meirhaeghe J, et al. Efficacy and safety of balloon kyphoplasty compared with nonsurgical care for vertebral compression fracture (FREE): a randomised controlled trial. Lancet. 2009;373(9668):1016-1024.

27. Dong $\mathrm{R}$, Chen $\mathrm{L}, \mathrm{Gu} \mathrm{Y}$, et al. Improvement in respiratory function after vertebroplasty and kyphoplasty. Int Orthop. 2009;33(6):1689-1694.

28. Lovi A, Teli M, Ortolina A, Costa F, Fornari M, Brayda-Bruno M. Vertebroplasty and kyphoplasty: complementary techniques for the treatment of painful osteoporotic vertebral compression fractures. A prospective non-randomised study on 154 patients. Eur Spine J. 2009;18(suppl 1):95-101.

29. Schofer MD, Efe T, Timmesfeld N, Kortmann H-R, 
Quante M. Comparison of kyphoplasty and vertebroplasty in the treatment of fresh vertebral compression fractures. Arch Orthop Trauma Surg. 2009;129(10):1391-1399.

30. Rousing R, Andersen MO, Jespersen SM, Thomsen K, Lauritsen J. Percutaneous vertebroplasty compared to conservative treatment in patients with painful acute or subacute osteoporotic vertebral fractures: three-months follow-up in a clinical randomized study. Spine (Phila Pa 1976). 2009;34(13):1349-1354.

31. Kallmes DF, Comstock BA, Heagerty PJ, et al. A randomized trial of vertebroplasty for osteoporotic spinal fractures. N Engl J Med. 2009;361(6):569-579.

32. Röllinghoff M, Siewe J, Zarghooni K, et al. Effectiveness, security and height restoration on fresh compression fractures: a comparative prospective suty of vertebroplasty and kyphoplasty. Minim Invasive Neurosurg. 2009;52(5-6):233-237.

33. Santiago FR, Abela AP, Álvarez LG, Osuna RMÁ, del Mar Castellano García M. Pain and functional outcome after vertebroplasty and kyphoplasty: a comparative study. Eur J Radiol. 2010;75(2):e108-e113.

34. Kasperk C, Grafe IA, Schmitt S, et al. Three-year outcomes after kyphoplasty in patients with osteoporosis with painful vertebral fractures. $J$ Vasc Intervent Radiol. 2010;21(5):701-709.

35. Liu JT, Liao WJ, Tan WC, et al. Balloon kyphoplasty versus vertebroplasty for treatment of osteoporotic vertebral compression fracture: a prospective, comparative, and randomized clinical study. Osteoporos Int. 2010;21(2):359-364.

36. Buchbinder R, Osborne RH, Ebeling PR, et al. A randomized trial of vertebroplasty for painful osteoporotic vertebral fractures. N Engl J Med. 2009;361(6):557-568.

37. Klazen CAH, Lohle PNM, de Vries J, et al. Vertebroplasty versus conservative treatment in acute osteoporotic vertebral compression fractures (Vertos II): an open-label randomised trial. Lancet. 2010;376(9746):1085-1092.

38. Bae H, Shen M, Maurer P, et al. Clinical experience using Cortoss for treating vertebral compression fractures with vertebroplasty and kyphoplasty: twenty four-month follow-up. Spine. 2010;35(20):E1030-E1036.

39. Movrin I, Vengust R, Komadina R. Adjacent vertebral fractures after percutaneous vertebral augmentation of osteoporotic vertebral compression fracture: a comparison of balloon kyphoplasty and vertebroplasty. Arch Orthop Trauma Surg. 2010;130(9):1157-1166.

40. Kumar K, Nguyen R, Bishop S. A comparative analysis of the results of vertebroplasty and kyphoplasty in osteoporotic vertebral compression fractures. Neurosurgery. 2010;67(3 suppl operative):ons171-188; discussion ons188.

41. Farrokhi MR, Alibai E, Maghami Z. Randomized controlled trial of percutaneous vertebroplasty versus optimal medical management for the relief of pain and disability in acute osteoporotic vertebral compression fractures. $J$ Neurosurg Spine. 2011;14(5):561-569.

42. Berenson J, Pflugmacher R, Jarzem P, et al. Balloon kyphoplasty versus non-surgical fracture management for treatment of painful vertebral body compression fractures in patients with cancer: a multicentre, randomised controlled trial. Lancet Oncol. 2011;12(3):225-235.

43. Blasco J, Martinez-Ferrer A, Macho J, et al. Effect of vertebroplasty on pain relief, quality of life, and the incidence of new vertebral fractures: a 12-month randomized follow-up, controlled trial. J Bone Miner Res. 2012;27(5):1159-1166.

44. Röder C, Boszczyk B, Perler G, Aghayev E, Külling F, Maestretti G. Cement volume is the most important modifiable predictor for pain relief in BKP: results from SWISSspine, a nationwide registry. Eur Spine J. 2013;22(10):2241-2248.

45. Van Meirhaeghe J, Bastian L, Boonen S, et al. A randomized trial of balloon kyphoplasty and nonsurgical management for treating acute vertebral compression fractures: vertebral body kyphosis correction and surgical parameters. Spine. 2013;38(12):971-983.

46. Clark W, Bird P, Gonski P, et al. Safety and efficacy of vertebroplasty for acute painful osteoporotic fractures (VAPOUR): a multicentre, randomised, double-blind, placebocontrolled trial. Lancet. 2016;388(10052):1408-1416.

47. Beall DP, Chambers MR, Thomas S, et al. Prospective and multicenter evaluation of outcomes for quality of life and activities of daily living for balloon kyphoplasty in the treatment of vertebral compression fractures: the EVOLVE trial. Neurosurgery. 2018;95(19):1729.

48. Firanescu CE, de Vries J, Lodder P, et al. Vertebroplasty versus sham procedure for painful acute osteoporotic vertebral compression fractures (VERTOS IV): randomised sham controlled clinical trial. BMJ. 2018;361:k1551.

49. Hirsch JA, Chandra RV. Resurrection of evidence for vertebroplasty? Lancet. August 2016:1-2.

50. Chandra RV, Maingard J, Asadi H, et al. Vertebroplasty and kyphoplasty for osteoporotic vertebral fractures: what are the latest data? Am J Neuroradiol. 2018;39(5):798-806.

51. Anderson PA, Froyshteter AB, Tontz WL. Metaanalysis of vertebral augmentation compared with conservative treatment for osteoporotic spinal fractures. $J$ Bone Miner Res. 2013;28(2):372-382.

52. Svedbom A, Alvares L, Cooper C, Marsh D, Ström O. Balloon kyphoplasty compared to vertebroplasty and nonsurgical management in patients hospitalised with acute osteoporotic vertebral compression fracture: a UK cost-effectiveness analysis. Osteoporos Int. 2012;24(1):355-367.

53. Leslie WD, Lix LM, Finlayson GS, Metge CJ, Morin $\mathrm{SN}$, Majumdar SR. Direct healthcare costs for 5 years postfracture in Canada. Osteoporos Int. 2013;24(5):1697-1705.

54. Edidin AA, Ong KL, Lau E, Schmier JK, Kemner JE, Kurtz SM. Cost-effectiveness analysis of treatments for vertebral compression fractures. Appl Health Econ Health Policy. 2012;10(4):273-284.

55. Anselmetti GC, Bernard J, Blattert T, et al. Criteria for the appropriate treatment of osteoporotic vertebral compression fractures. Pain Physician. 2013;16(5):E519-E530.

56. Hulme PA, Krebs J, Ferguson SJ, Berlemann U. Vertebroplasty and kyphoplasty: a systematic review of 69 clinical studies. Spine (Phila Pa 1976). 2006;31(17):1983-2001.

57. McGuire R. AAOS Clinical practice guideline: the treatment of symptomatic osteoporotic spinal compression fractures. J Am Acad Orthop Surg. 2011;19(3):183-184.

58. Hansen EJ, Simony A, Rousing R, Carreon LY, Tropp $\mathrm{H}$, Andersen MO. Double blind placebo-controlled trial of percutaneous vertebroplasty (VOPE). Global Spine. 2017;6:1-6.

59. National Institute for Health and Care Excellence. Percutaneous vertebroplasty and percutaneous balloon kyphoplasty for treating osteoporotic vertebral compression fractures. 
https://www.nice.org.uk/guidance/ta279. Access December 3, 2018.

60. Van Meirhaeghe J, Bastian L, Boonen S, Ranstam J, Tillman JB, Wardlaw D. A randomized trial of balloon kyphoplasty and nonsurgical management for treating acute vertebral compression fractures. Spine. 2013;38(12):971-983.

61. Hirsch JA, Beall DP, Chambers MR, et al. Management of vertebral fragility fractures: a clinical care pathway developed by a multispecialty panel using the RAND/UCLA Appropriateness Method. Spine J. [In press].

Disclosures and COI: OCL reports no disclosures. DB reports the following disclosures unrelated to the preparation of this manuscript: compensation, grants, and personal fees from Medtronic related to consultancy, research and teaching; grants from Benvenue, Alphatech Spine, Medical Metrics, Liventa, Vexim, and Mesoblast; consultancy fees from DEFINE and Osseon; other from Lilly, Smith \& Nephew, Biomet, Vertiflex, Synthes, and Integral Spine Solutions. KO reports the following disclosures unrelated to the preparation of this manuscript: employee and shareholder of Exponent, a scientific and engineering consulting firm. Exponent has been paid fees by entities in the biomedical arena for consulting services, including Zimmer Biomet, Stryker Orthopaedics, Joerns Healthcare, Ossur, DJO, Ethicon, Ferring Pharmaceuticals, Pacira Pharmaceuticals, Paradigm Spine, and Medtronic. ML reports the following disclosures unrelated to the preparation of this manuscript: royalties from Choice Spine Thunderbolt, stock ownership in OrthogenRx, stock options with OrthoKinematics, intellectual property with Transformer Spine.

Corresponding Author: Morgan Lorio, MD, FACS, Hughston Clinic Orthopaedics, 2400 Patterson Street, Nashville, TN 37203. Phone: (615) 3426300; Email: mlorio@hughston.com.

Published 22 February 2019

This manuscript is generously published free of charge by ISASS, the International Society for the Advancement of Spine Surgery. Copyright (C) 2019 ISASS. To see more or order reprints or permissions, see http://ijssurgery.com. 